Danielle Xavier de Campos, Tatiane Alvarenga Sanchez, Fabiana de Oliveira Alves

\title{
O IMPACTO DA ATUAÇÃO DA COMISSÃO INTRA-HOSPITALAR EM UM HOSPITAL PÚBLICO
}

Eixo temático: Avaliação e Qualidade do Cuidado

Introdução: O sistema de transplantes de órgãos e tecidos com doadores falecidos no Brasil é seguro e bem estruturado. O número deste tipo de doador tem aumentado no país de uma forma geral, embora encontramos algumas dificuldades no processo, como a subnotificação, notificação tardia, parada cardiorrespiratória e recusa familiar.

Objetivo: Analisar o número de notificações de morte encefálica (ME) e doadores efetivos após reestruturação da Comissão Intra-hospitalar de Transplante (CIHT) de um Hospital Público.

Métodos: Estudo retrospectivo e descritivo, realizado em um Hospital Público de Grande Porte localizado na região metropolitana de São Paulo. Foram coletados dados do período de 01 de janeiro de 2016 a 31 de outubro de 2018.

Resultados: Em 2016 foram realizadas 22 notificações a Central de Transplantes, destas notificações, 45 \% tornaram-se doações efetivas. Dos doadores efetivos, a média de idade foi de 47 anos, $70 \%$ do sexo masculino e em relação a causa de $M E, 60 \%$ das causas foram decorrentes de traumatismo crânio encefálico. No ano de 2017 realizadas 26 notificações, havendo um aumento de $18 \%$ no número de notificações e $20 \%$ de doadores efetivos. Dos doadores efetivos, a média de idade foi de 45 anos, $58 \%$ do sexo feminino e $58 \%$ das causas de ME foram decorrentes de acidente vascular encefálico (AVE).Em 2018 foram 44 notificações e 26 doações efetivas, aumento de $117 \%$ no número de doações efetivas, e aumento de $69 \%$ no número de notificações. Dos doadores efetivos, a média de idade foi de 51 anos, $69 \%$ do sexo masculino e $62 \%$ das causas de ME foram decorrentes de AVE.O aumento significativo no número de notificações no ano de 2018 , comparado aos anos anteriores, reflete as ações exercidas pela CIHT,entre elas, busca ativa de potenciais doadores realizado pelas enfermeiras da $\mathrm{CIHT}$, auxilio na manutenção e no processo de diagnóstico da morte encefálica e educação continuada dos membros da CIHT e dos colaboradores da instituição in loco e através de palestras.

Conclusão: A atuação da CIHT mostrou-se efetiva. A identificação precoce do potencial doador , favoreceu consideravelmente $\mathrm{o}$ aumento das notificações e consequentemente o aumento expressivo dos doadores efetivos. 